\title{
A TIME SERIES ANALYSIS OF U.K. LOTTERY SALES: LONG AND SHORT RUN PRICE ELASTICITIES
}

\author{
Lisa Farrell, Edgar Morgenroth and Ian Walker †
}

\section{INTRODUCTION}

The widespread popularity of lotteries in general and the introduction of the U.K. National Lottery in November 1994 has generated concern over the potential addictiveness of gambling and numbers games in particular. Indeed, the Director General of the Office of the National Lottery (who regulates the U.K. game that is operated by a private sector franchisee) is directed by the Secretary of State not to license games that encourage 'excessive participation'. Despite this concern there has been no economics research into the extent to which lottery participation is subject to addiction.

Most modern lottery games are variations of the pari-mutuel 'lotto' design: players buy a ticket where they have chosen $m$ numbers from $n$; when the draw takes place $m$ numbered balls are selected randomly from $n$; prizes are shares of a proportion of the stakes and the remaining portion of the stakes (the take-out) is used to administer the game, pay the ticket outlets, and cover tax liabilities and other charges; and prizes are awarded to ticket holders that match different numbers of the balls drawn (usually there is a large jackpot prize pool for those few that match all $m$, and smaller prize pools are shared by those who match $m-1, m-2$ etc.). The distinctive feature of such games is that there may be no $m$-ball matches in a given draw in which case the jackpot is 'rolled-over' to the following draw. Rollovers give rise to variations in the expected value (defined as the price of a ticket minus the expected winnings) of tickets between regular draws (where the jackpot from the previous draw has not rolled over) and rollover draws. This generates systematic variation in the level of sales across draws because a rollover induces an exogenous change in price that causes a movement along the demand curve.

The excess of revenue over prize payouts, which is approximately 50 percent of sales, is divided between the operator (5\%, on average), the distributor $(5 \%)$, sales tax $(12 \%)$, and 'good causes' $(28 \%$, on average)

$\dagger$ We are grateful to Richard Cornes, participants at a Keele workshop, and an anonymous referee for helpful comments. The usual disclaimer applies. The data used here was made available to us by Camelot PLC and from the Lottoshop World Wide Web page. This research was funded by the UK Economic and Social Research Council under research grant R000236821.

\section{3}

(C) Blackwell Publishers Ltd, 1999. Published by Blackwell Publishers, 108 Cowley Road, Oxford OX4 1JF, UK and 350 Main Street, Malden, MA 02148, USA. 
which is deposited with several 'Distribution Funds' and then allocated to charitable and other causes. This is typical of most lotto games which are run with the aim of raising revenue for such causes or for general government expenditure.

Traditional economic theory assumes that preferences are exogenous and has difficulty addressing the issue of addiction. Becker and Murphy (1988), hereafter BM, present a theoretical model where individuals maximize utility over a good to which they can become addicted. A distinction between the long- and short-run elasticities is an important consequence of the presence of addiction. In a model with addiction the long run elasticity is greater than the short run elasticity. That is, we would expect increases in consumption which arise due to a fall in price to be magnified over time given that the good is addictive. Thus rollovers can induce higher sales in future draws as well as the current draw.

Cook and Clotfelter (1993) find that rollover-induced variation in the expected value of a ticket as an important determinant of sales ${ }^{1}$. Gulley and Scott (1993) also include the expected value in a study of U.S. lottery participation. Farrell and Walker (1999) also use the expected value to identify the price elasticity using cross section data pooled across regular and rollover draws. Here we apply a similar methodology to estimate the elasticity of demand for the U.K. National Lottery using time series data, and to test for addiction among players which results in the long-run elasticity exceeding the short-run elasticity.

The realization that the true elasticity can be identified from changes in the expected return to a ticket caused by rollovers is an important observation as the face value of a ticket is fixed (at $£ 1$ in the case of the U.K. National Lottery). However the expected price of the ticket is not the face value, but the amount that is not returned in the form of prices (i.e. $(1-V)$ where $V$ is the expected value of a ticket). Since there is observable variation in the expected value, due to the presence of rollovers, there is implicitly price variation from which one can estimate the price elasticity of demand.

There is, however, one potential problem with our approach. We are relying for identification on the existence of rollovers and these should occur with relative infrequency ${ }^{2}$. Surprisingly this has not been the case for the U.K. lottery. Rollovers have, in practice, occurred with a much higher frequency than would be expected by statistical chance. Farrell et al. (1999) show that one reason for this is that players appear to select their numbers

\footnotetext{
${ }^{1}$ However due to collinearity between the expected value and the size of the jackpot which is also included as a regressor, this variable performs poorly in their model.

${ }^{2}$ The rollover probability for level of sales of $C$, if players select their numbers randomly, is given by $\left(1-(n ! / m !(n-m) !)^{-1}\right)^{C}$. So in the case where $n=49$ and $m=6$ it follows that the chance of a given ticket winning the jackpot is $1 / 14$ million so with sales of about 70 million per draw we would expect to see approximately 5 jackpot winners per week. With a standard deviation of approximately 2 , this implies that there should be no winners in approximately $1 \%$ of draws.
} 
in a non-uniform way. As a result more players pick the same combinations of numbers than would otherwise occur if they selected their numbers uniformly. This leads to a lower coverage of the possible combinations of numbers and so increases the probability of a rollover occurring ${ }^{3}$.

We use data from the inception of the game until the introduction of the second weekly draw. By including a lag of sales in the model we are able to identify the long run effects of price changes as well as the short run effects ${ }^{4}$. The importance of the price elasticity relates to the regulatory framework - the U.K. game is effectively required to maximise sales which implies a price elasticity of -1 . In contrast profit maximisation will require the elasticity to be -1.06 , given the marginal costs implied by the game design for the U.K. Thus we would like to be able to discriminate between these two to test the effectiveness of regulation. Moreover, the level of addiction, in comparison with other goods such as cigarettes, is itself of interest.

The paper is organised as follows: section II summarizes Becker and Murphy's (1988) model of addiction and introduces the lotto expected value function; section III presents the econometric methodology; section IV presents the results; and section V summarizes and concludes.

\section{THEORETICAL FRAMEWORK}

Becker and Murphy's theoretical model distinguishes between myopic addiction, where individuals only take account of past purchases in determining present consumption, and rational addiction, where individuals are forward looking and so also take account of expected future prices, and therefore future consumption, when making current consumption decisions. If rational addiction is present then a fall in expected future prices will increase both future sales and present consumption. That is, to get the maximum utility from the anticipated increase in future consumption individuals need to build up their stock of addiction through increased consumption today. It is possible to test for 'rationality' in this sense in our application because it depends on there being variations in expected future prices. There is some variation in the expected future prices because this is the probability weighed sum of rollover and non-rollover prices and these prices vary systematically across the data because rollovers affect the expected value. That is, a rollover in the current draw affects the expected price in the next draw. Thus our estimates can, in principle, be used to examine the rationality or otherwise of addiction.

The model set out in BM considers utility maximisation defined over a

\footnotetext{
${ }^{3}$ The introduction of a random number selector into the lottery terminals, from week 70 , has increased the weekly coverage and a slight impact on the number of rollovers appears to be visible in the data.

${ }^{4}$ The introduction of an autoregressive component is discussed later.
} 
good assumed to be addictive. Addiction implies that current consumption will depend, in part, on the stock of addiction generated by past consumption. Single period models imply that current consumption is independent of past consumption under the conventional assumption of intertemporal additive separability. This is relaxed in BM, simply by allowing this period's utility to be a function of both present and past consumption of the addictive good. The utility function can thus be expressed as

$$
U_{t}=U\left(y_{t}, c_{t}, c_{t-1}, e_{t}\right),
$$

where $y_{t}$ is a composite commodity, $c_{t}$ is the current period consumption of the potentially addictive good, $c_{t-1}$ is the one period lag of $c_{t}$ and $e_{t}$ captures the effects of unobservable variables and current period shocks on utility. Past consumption of the addictive good enters directly into this period's utility since it is a sufficient statistic for the stock of addiction.

As this is a utility maximization problem we must assume concavity of the utility function. However in the context of the purchase of lottery tickets this presents a problem. Participating in an unfair gamble is clearly at odds with conventional expected utility theory. One generalisation is to postulate that individuals are risk averse, and so would normally reject unfair bets, but that participating in the lottery generates some additive positive nonpecuniary effect on well-being 5 . In order to maintain the concavity assumption it is further necessary to assume that the utility from the act of playing itself is diminishing in the number of tickets purchased. The high level of participation, from across the income distribution, and the low levels of expenditure per person seem to be consistent with this motivation for playing.

Consumers choose $c_{t}, y_{t}$ so as to maximise this (expected) utility function over their (infinite) life-time subject to the usual budget constraint that the life-time discounted sum of consumption must be equal to the present value of wealth, at the maximum. This is, the problem is to

$$
\max \sum_{t=1}^{\infty} \beta^{t-1} U\left(c_{t}, c_{t-1}, y_{t}, e_{t}\right) \text { such that } \sum_{t=1}^{\infty} \beta^{t-1}\left(y_{t}+P_{t} c_{t}\right)=A^{0} \text {, }
$$

where $\beta=1 /(1+\rho), \rho$ is the rate of time preference, $P_{t}$ is the current price of the good and $A^{0}$ is the present value of wealth (including the expected winnings from lottery play). BM show that the solution to this problem for a utility function quadratic in $c_{t}, y_{t}$ and $e_{t}$, is a linear difference equation whereby current consumption of the addictive good is a function of past and future consumption, the current price and the error terms ${ }^{6}$. Aggregated across all individuals they obtain the following equation

$$
C_{t}=\alpha+\theta C_{t-1}+\beta \theta C_{t+1}-\theta_{1} P_{t}+\theta_{2} e_{t}+\theta_{3} e_{t+1},
$$

\footnotetext{
${ }^{5}$ See Conlisk (1993) and Quiggin (1991) for a full analysis of such models.

${ }^{6}$ For a full derivation from the associated first order conditions see Becker and Murphy (1988).
} 
where $C_{t}, C_{t+1}, C_{t-1}$ are the aggregate current, future and past consumption's respectively, and $\alpha, \theta, \theta_{1}, \theta_{2}, \theta_{3}$ are preference parameters from the quadratic utility function.

The level of addiction of a good is higher the greater the reinforcement of past consumption on present consumption, that is, the higher is $\theta$. The theory suggests that both the lag and lead of sales will be significant determinants of consumption whose coefficients differ only by the discount factor. BM refer to this as rational addiction. However there are two qualifications to this. First, as individuals tend towards the myopic then, $\rho \rightarrow \infty$ and so $\beta \rightarrow 0$. In this extreme case only the lag will have a significant coefficient; a case which BM call myopic addiction. Secondly, when there is no variation in expected future prices then data cannot identify the rate of time preference since future sales only appears because of expected movements in future prices. Here, there is expected variation in future prices - in each draw individuals expect the price in the next draw to be determined by the weighted sum of the expected values when there is a rollover and when there is no rollover, where the weights are then given by the probabilities that these events occur. While it is the case that rollovers are random events the expected future value of the price depends on whether a rollover has already occurred: the expected price in the next draw will be higher if the current draw has featured a rollover. Thus, we estimate the model in (3) as well as the special cases of myopic addiction and no addiction. The short and long run price elasticities, calculated at the mean, are therefore given by $\left.\varepsilon\right|_{C_{t-1}} \equiv \theta_{1}((1-\bar{V}) / \bar{C})$ and $\left.\varepsilon\right|_{C_{t-1}} \equiv$ $\left(\theta_{1} /\left(1-\theta_{1}\right)\right)((1-\bar{V}) / \bar{C})$ respectively.

Estimating (3) requires data on $V$. The formal expression for the expected value of a lottery ticket was first derived in Sprowls (1970) and has subsequently been adopted and refined in Lim (1995) and Scoggins (1995). Here we will consider the case where players are assumed to select their numbers uniformly ${ }^{7}$. The size of the jackpot is equal to the sales revenue times the proportion of ticket sales in week $t$ going to the jackpot prize pool and plus any rolled over prize money from the previous draws draw. We denote $C_{t}$ as the sales revenue (aggregate consumption) and $R_{t}$ as the amount rolled over; which in most draws will be zero. Finally $\pi_{6 t}$ is the proportion of ticket sales in draw $t$ going to the jackpot prize pool. The size of the jackpot in draw $t$, is thus expressed as

$$
J_{t}\left(\pi_{6 t}, R_{t} ; C_{t}\right)=R_{t}+\pi_{6 t} C_{t} .
$$

The probability that this jackpot is won, $p_{6}$, is determined by the characteristics of the game as explained earlier. The probability of there being a

\footnotetext{
${ }^{7}$ Cook and Clotfelter (1993), pp 636-7, speculate that the theoretical structure of the game is unchanged if individuals pick their numbers non-randomly (they call this 'conscious selection'). Farrell et al (1996) consider this more complex conscious-selection case and prove that the most important theoretical properties of the game are indeed unaffected by this generalisation. They also show that conscious selection has minimal impact on the estimated elasticity.
} 
rollover is equal to the probability that none of the players win the jackpot, $\left(1-p_{6}\right)^{C_{t}}$. In the case of the U.K. National Lottery there are also smaller prizes awarded for matching any five, four or three of the main numbers and a further prize pool for matching any five main numbers plus a seventh bonus ball, $(5+b)$. The expected value of holding a lottery ticket taking account of the smaller prizes is therefore ${ }^{8}$

$$
V\left(R_{t}, \pi_{6 t}, \pi_{j t}, p_{6} ; C_{t}\right)=\left\{\left[\left(1-\left(1-p_{6}\right)^{C_{t}}\right]\left[\pi_{6 t} C_{t}+R_{t}\right]+\sum_{j} \pi_{j t} C_{t}\right\} / C_{t}\right.
$$

where $j=3,4,5,5+b, p_{6}$ is the probability of a single ticket winning the jackpot, $p_{j}$ is the probability of correctly selecting any $j$ numbers, $\pi_{6 t}$ is the proportion of ticket sales in draw $t$ allocated to the jackpot prize pool and $\pi_{j t}$ is the proportion of ticket sales going to the $j^{\text {th }}$ prize pool in draw $t$ so that, $\sum_{j} \pi_{j t}+\pi_{6 t}=(1-\tau), j=3,4,5,5+b$, where $\tau$ represents the takeout. The takeout is the proportion of sales revenue not returned in the form of prizes which covers the operator's costs, profits, tax, and, in the UK, contributions to a number of good causes ${ }^{9}$. It is straightforward (see Farrell and Walker (1998)) to show that $V_{R}>0, V_{p_{6}}>0$, and $V_{t}<0$ where subscripts indicate partial derivatives. The effects of the level of sales, $C_{t}$, is more difficult. In the case where $R=0$ it is simple to show that $V_{C_{t}}>0$ and $V_{C_{t} C_{t}}<0$, but in general

$$
V_{C_{t}}=\left(p_{6} C_{t}\left(1-p_{6}\right)^{C_{t}}\left((1-\tau) C_{t}+R_{t}\right)-R_{t}\left(1-\left(1-p_{6}\right)^{C_{t}}\right)\right) / C_{t}^{2}
$$

which is not necessarily monotonic and Figure 1 depicts the possibilities together with the relationship for $R=0$. $V(R)$ always asymptotes towards $(1-\tau)$, but for $R>0$ it is from above and at a slower rate than for $R=0$ when it is faster and from below. For $R>0$ the relationship may attain a maximum for some finite $C_{t}$ but for sufficiently large $R$ the relationship will be monotonically decreasing. Notice that $V$ is always higher in rollover draws than in regular draws, irrespective of the level of sales. Thus, it is impossible to arbitrage away the differences in $V$ no matter what the variation in sales. This implies that there will always be some exogenous variation in $V$ arising from the random incidence of rollovers. It is, indeed, possible in theory for the expected value to exceed unity, the cost of a ticket, so the net expected return becomes positive.

Figure 1 shows how the expected return varies with the level of aggregate sales. This is effectively the inverse supply function for industry and it

\footnotetext{
${ }^{8}$ It will be assumed, for expositional convenience, that the smaller prizes do not rollover. Whilst it is possible for them to do so, in practice they never have and the probability of them doing so is very small.

${ }^{9}$ For the UK National Lottery Treasury duty is $12 \%$ of ticket sales, the retailer's commission is $5 \%$, operator's costs and profits are $5 \%$ on average, and 'good causes' get $28 \%$ on average.
} 


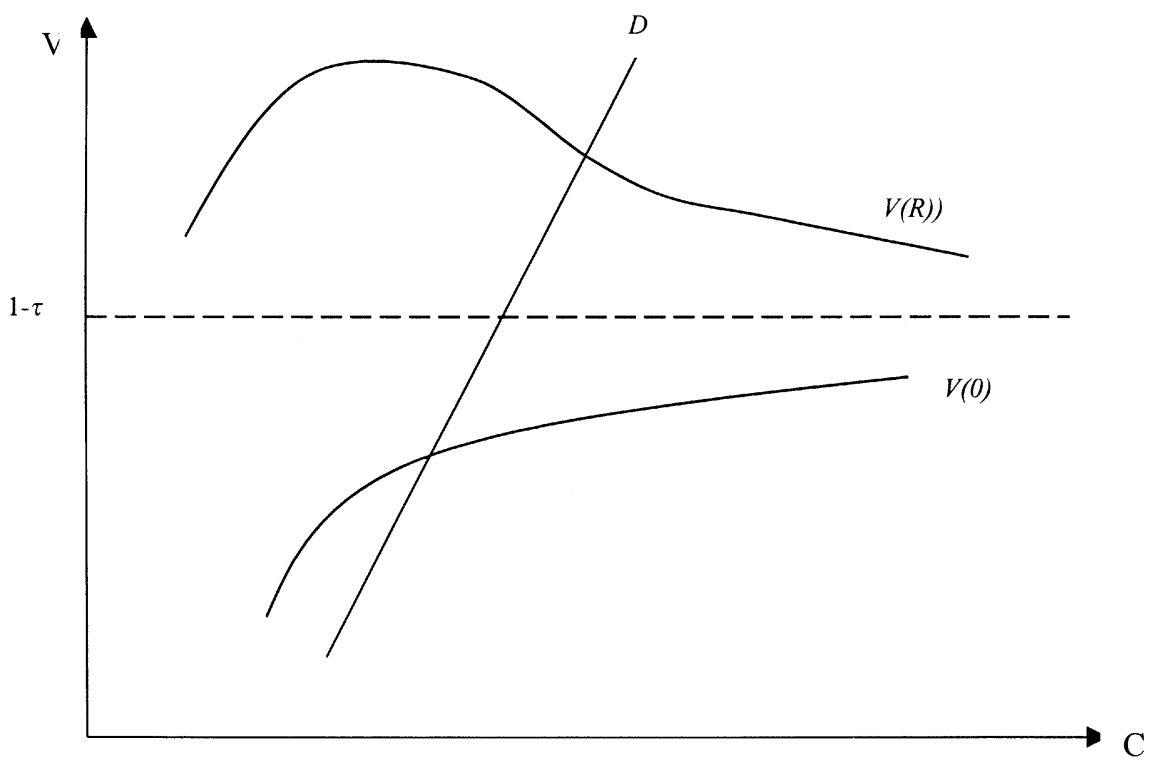

Figure 1. The Relationship between Sales and the Expected Return

illustrates why it is unlikely that the expected return would ever be greater than the cost of a ticket since it would require a low level of sales in a draw with a large jackpot accumulated from previous rollovers. Superimposing an aggregate demand function $D$ in Figure 1 shows how a rollover shifts the inverse supply function and induces a movement along the demand curve. Thus, it is rollovers that identify the price elasticity otherwise draw to draw variation is simply a result of draw specific shocks to demand that induce endogenous variation in $V$ along the inverse supply curve for $R=0$.

\section{ECONOMETRIC METHODOLOGY}

The theory suggests that equation (3) should form the basis for our econometric modelling. The functional form arises from the assumed quadratic in levels utility function and it is difficult to derive explicit forms from other specifications. One complication is that the expected value is endogenous in this model since it is itself a function of the number of tickets sold in a given draw. In order to account for this we estimate the model using instrumental variables, instrumenting the expected value of a lottery ticket with the size of the rollover.

Following BM and Becker, Grossman and Murphy (1994), hereafter BGM, we test the significance of last period's consumption by incorporating the lagged value of the dependent variable in a regression of current sales on the instrumented current expected value. This allows us to see if past 
behaviour reinforces present consumption. However the introduction of a lag of the dependent variable is likely to lead to serial correlation due to the intertemporal correlation of unobservables. Consequently it is necessary to instrument the lag using the same instruments as those used to instrument the expected value. BGM instrument using price but in the case of lottery play the price (expected value) is itself endogenous and therefore not a suitable instrument. The exogenously determined rollovers and their size provides a reasonable set of instruments in this case. In any case including a lag of the dependent variable we distinguish between the long-run and short-run effects of a change in the return to a lottery ticket ${ }^{10}$.

$\mathrm{BM}$ emphasises the possibility of rational addiction and uses variations in expected future prices to capture this possibility. Here, the expected price in the next draw depends on the difference between the expected value of a ticket if there is a rollover in the current draw and the expected value when there is no rollover. This difference is, in practice, close to being a constant since in the U.K, the game features large sales so that the price is largely independent of variations in sales. Thus, our data is unlikely to yield a precise estimate of the discount rate that could be used to judge the plausibility of the rational addiction hypothesis. Our data records aggregate weekly National Lottery ticket sales per draw for the on-line game only (i.e. excluding scratch cards). There are 116 observations starting from the first week that lottery tickets went on sale in November 1994 and end in February 1997 when a midweek draw was introduced ${ }^{11}$. Over this period total sales per draw averaged approximately $£ 68.7$ million and reached more than $£ 100$ million in double rollover draws. Figure 2 shows the sales revenue per draw for the duration of the data set. Over this period there were 18 single rollovers and 2 double rollovers, (a double rollover occurs when the jackpot is not won for two consecutive draws.

Since tickets cost $£ 1$ each we can directly infer revenue per draw from the sales and from sizes of the prizes won we can derive the proportion of ticket sales allocated to each prize pool each draw. One feature of the U.K. game is that 3-ball winners receive a flat prize of $£ 10$ rather than a share of a pool and that the pools for 4-ball, 5-ball etc winners then receive shares of the remainder. Thus we compute the expected number of 3-ball winners (approximately the number of tickets sold divided by 57) and then calculate the contribution of the 4-ball, etc prize pools to the expected value of a ticket accordingly, allowing for rollovers to add to the jackpot 6-ball prize pool.

\footnotetext{
${ }^{10}$ The extent to which the estimated elasticities can be applied to the effects of permanent changes in price is unclear. Rollover induced price shocks are temporary and players may react differently to permanent changes such as alterations in the design of the lottery. That is, players may engage in intertemporal substitution in response to anticipated rollovers. However, our preliminary analysis of the data post the introduction of the Wednesday, which increased the potential for such behaviour, suggests that this is not a feature of the data.

${ }^{11}$ This leads to new dynamic issues that take us beyond the scope of this paper.
} 


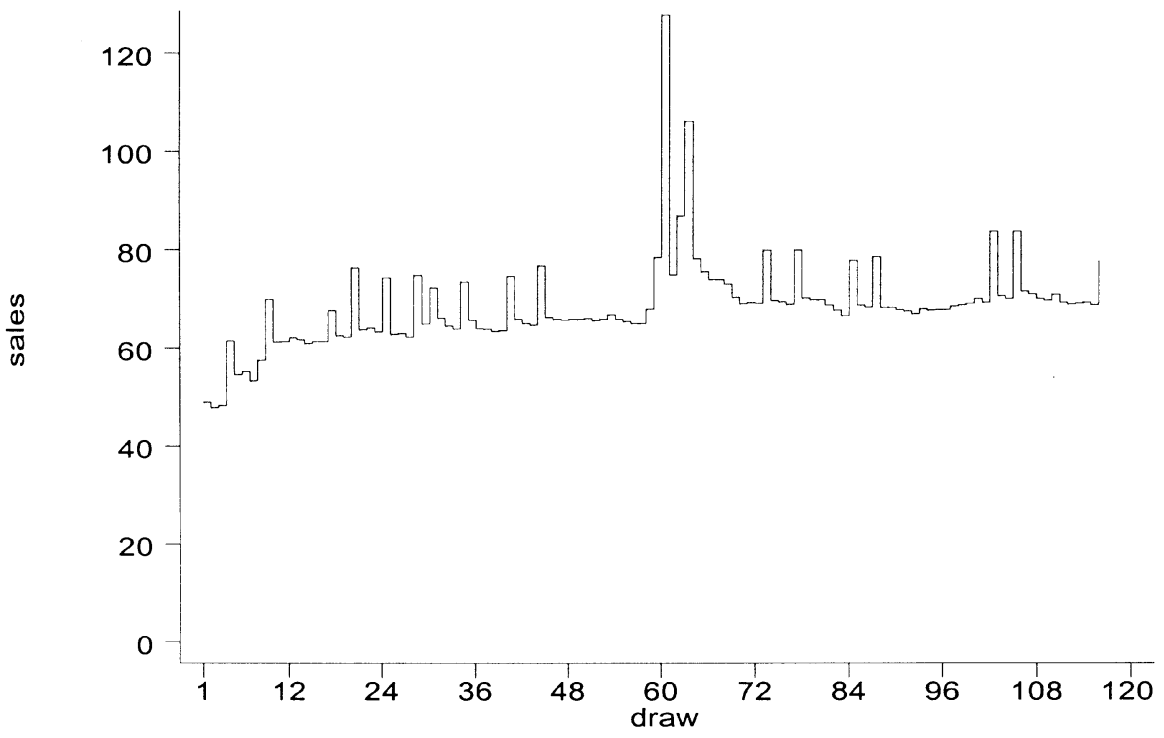

Figure 2. UK National Lottery Ticket Sales Nov. $94-$ Feb. $97^{12}$

\section{RESULTS}

Before we turn to the results two more data issues need to be addressed. It is now well known that many time series are nonstationary which, when these variables are used in a regression, can lead to a spurious regression problem (see Granger and Newbold (1974)). In order to avoid this problem it is necessary to identify the order of integration of the data. This was achieved using the widely accepted Augmented Dickey-Fuller test (see Dickey and Fuller $(1979,1981))$. The results from this test ${ }^{13}$ conclusively reject the null hypothesis of a unit root for both sales and the expected value and it is therefore valid to estimate the relationship between them using conventional regression techniques.

Cook and Clotfelter (1993) drop the observations for the period when the product was new. Here, we wish to preserve the largest possible sample size

\footnotetext{
${ }^{12}$ Figure 2 might suggest that an ARIMA model may give a good characterisation of the data, however the $R^{2}$ for the structural model is approximately twice that of any ARIMA model we estimated and is thus a significantly better characterisation of the data.

${ }^{13}$ The test statistic for $C$ was -3.115 and for $V$ was -3.039 compared to a critical value -2.89 . The test was run with a constant and four augmenting lags but no trend. The Dickey-Fuller test is biased against rejection of a unit root in the presence of structural breaks. Given this we also applied Zivot-Andrews tests (Zivot and Andrews, (1992)) which test the null of a unit root against that of stationarity with structural breaks. This test is particularly useful as it identifies the breakpoints endogenously and is therefore not subject to the same pre-test bias as are more conventional tests. Again the hypothesis of a unit root was rejected.
} 
and attempt to control for the rise in sales at the beginning of the period by including the (log of) the number of sales terminals ${ }^{14}$. The operator's contract specified the growth path in the number of terminals and it can therefore be regarded as exogenous.

Our initial estimates of (3) indicated that the coefficient on the lead of sales was small, very badly determined and implied an extremely implausible rate of time preference ${ }^{15}$. Thus, we proceeded directly to the myopic model and the results for this and the no addiction models are presented in Table 1.

In the conventional, no addiction, model we find that all the coefficients have the expected sign and are statistically significant. Attempts to generalize the specification to allow for a time trend proved not to add to the model once we had controlled for the variation in the number of sales terminals. In the estimates of the myopic addiction model, which includes a lag of consumption, the coefficient on lagged consumption is positive and significant suggesting that lottery play is addictive since consumption in the previous period has a positive and significant effect on consumption in this period. The coefficient on the expected value changes only marginally

TABLE 1

Two Stage Least Squares Estimates and Tests

\begin{tabular}{lcc}
\hline & Conventional specification & Addiction specification \\
\hline$C_{t-1}$ & - & $0.33(0.11)$ \\
$V_{t}$ & $136.60(32.85)$ & $134.82(5.02)$ \\
Constant & $-193.05(28.04)$ & $-145.70(17.92)$ \\
\hline $\bar{R}^{2}$ & 0.67 & 0.74 \\
\hline LM (AR1) & $2.55(0.11)$ & $4.18(0.04)$ \\
LM (AR2) & $2.52(0.08)$ & $2.20(0.11)$ \\
LM (AR3) & $3.95(0.01)$ & $2.11(0.10)$ \\
LM (AR4) & $4.18(0.00)$ & $1.65(0.16)$ \\
Hetero (squared) & $6.26(0.00)$ & $3.60(0.00)$ \\
Hetero (cross product) & $5.04(0.00)$ & $2.75(0.00)$ \\
ARCH & $0.66(0.41)$ & $1.87(0.17)$ \\
\hline
\end{tabular}

Note: The dependent variable is the level of sales. The log of terminals is also included. The standard errors in parentheses are heteroskedasticity robust (using White's method). LM statistics are for AR1 etc and are Breusch-Godfrey LM tests for first and higher order serial correlation which are distributed as chi-squared - the terms in parentheses are the $\mathrm{P}$ values for these tests. Tests for heteroskedasticity where we include the squares of the $X$ variables and for the cross products.

\footnotetext{
${ }^{14}$ Dropping the first 19 observations does not change the coefficients significantly when compared with the estimation including the sales terminals variable.

${ }^{15}$ We found that the coefficients on the lag and the expected value were insensitive to the inclusion of the lead of sales and to the inclusion of other controls. For example, for a model with no other controls we found that the estimate of $\beta \theta$ was 0.08 with a standard error of 0.06 implying that the weekly rate of time preference was approximately 12 . BGM report similar, but less acute, problems with estimated rates of time preference between 0.56 and 2.23.
} 
relative to that of the conventional model. That is, sales increase in rollover weeks and while they fall afterwards they remain higher than prior to the rollover occurring ${ }^{16}$. This means that rollovers heighten the potential addictiveness of numbers games; the more rollovers, the more potential there is for addiction to develop. We can see that post-rollover effect in Figure 3 where we plot how sales evolve, on average, after rollovers in the data and compare this with the predicted post rollover sales. A typical rollover raises sales by 20 percent but sales do not return to their previous level immediately. Thus a rapid succession of rollovers can effectively ratchet sales upwards.

It is notable that we find a significant but relatively small addiction coefficient when compared to those found by BGM for cigarette addiction. Our estimate of the coefficient on the lag of consumption is 0.33 whereas the corresponding coefficient reported for cigarette consumption are typically of the order of 0.45 . This suggests that lottery play is less addictive than cigarette consumption, which seems plausible given that lottery play is not physically addictive.

We conducted exhaustive testing of the myopic addiction specification to check for: mispecified dynamics, stability of coefficients, etc. We also tested for the inclusion of additional lags using pseudo-F tests (see Davidson and Mackinnon (1993) which allows for the use of instrumental variables) which showed clearly that the myopic addiction model has the correct

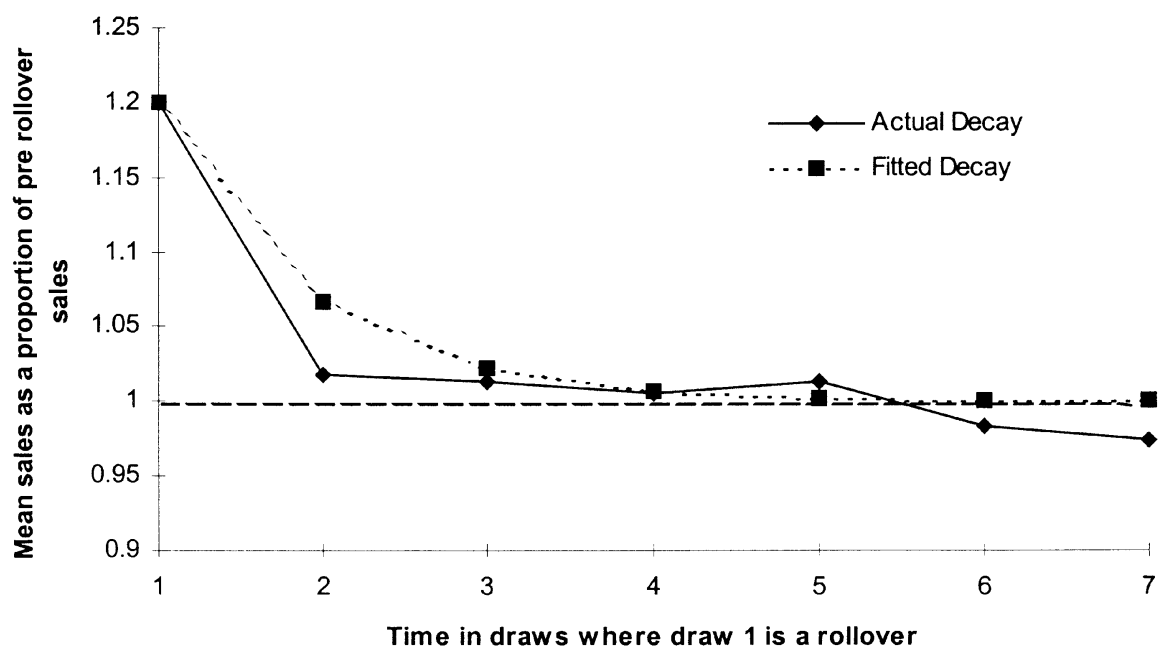

Figure 3. Post Rollover Sales Behaviour

\footnotetext{
${ }^{16}$ The lottery industry refers these higher than average sales following a rollover as the halo effect.
} 
dynamic specification ${ }^{17}$. The LM statistics reported in the table for first and higher order serial correlation indicate their absence in the myopic addiction model. The heteroskeasticity tests indicate its absence. The ARCH test (Engle (1982)) amounts to a rejection of ARCH.

We tested for stability using tests proposed by Hansen $(1992)^{18}$ and find that each individual slope coefficient is stable and that although they are jointly unstable we find that it is the constant and the terminals coefficients that are responsible for this ${ }^{19}$. Thus we are reasonably confident that we have captured the correct rollover effect and the short run dynamics post rollover that are important for policy.

Table 2 reports the long and short run elasticities. The short run elasticity gives the response in period $t$ to a change in the expected value of a ticket, whereas the long-run effect pertains to the response to a change in the expected value across all periods. Thus the long-run effect must exceed the short-run effect. The elasticities show that there is a negative relationship between sales and the price of a ticket and therefore a positive relationship between sales and expected value ${ }^{20}$.

The long-run effect does exceed the short-run as predicted, although not significantly so. From this estimated long-run elasticity of -1.55 , and its standard error of 0.04 , we are clearly able to reject both revenue maximisation, which implies an elasticity of -1.00 , and profit maximisation, which implies an elasticity of -1.06 . However we could reject neither with the short-run estimates ${ }^{21}$. Thus our long-run result seems to suggest that the pricing of the product is not consistent with the regulator's objective and the

TABLE 2

Long and Short Run Elasticities

\begin{tabular}{lll}
\hline Elasticity & Conventional & Myopic Addiction \\
\hline Long-run & $-1.05(0.25)$ & $-1.55(0.04)$ \\
Short-run & & $-1.04(0.04)$ \\
\hline
\end{tabular}

Note: the standard errors in parentheses were obtained by scaling by the ratio of the mean price to the mean sales.

\footnotetext{
${ }^{17}$ Testing one lag against none yields an $\mathrm{F}$ statistic of 31.52, and testing one lag against two, three and four lags yielded F statistics of $0.20,0.90$ and 0.59 respectively.

${ }^{18}$ Similar tests are proposed by Nyblom (1989) and Andrews (1993).

${ }^{19}$ The test value for the joint stability of coefficients was 7.07 compared to a critical value of 1.47, and for $C t-1, V, \operatorname{Ln} T$, the constant, and the variance of the residuals were $0.34,0.35,0.40$, 0.40 , and 0.14 compared to a critical value of 0.47 at the $5 \%$ level.

${ }^{20}$ This is a significant improvement upon those results offered by Cook and Clotfelter (1993).

${ }^{21}$ At the margin Camelot retain $1 \%$ of their $2 \%$ share of the purchase price of a ticket, and the vendor received 5\% implying that marginal costs are $6 \%$ of revenue. Assuming constant costs and noting that $M R=M C=P(1+(1 / \varepsilon))$, what $\varepsilon$ is the price elasticity, profit maximisation implies that $1+1 / \varepsilon=0.06$ so that $\varepsilon=-1.06$, while revenue maximisation implies that $M R=0$ so that $\varepsilon=-1$.
} 
regulator could elicit greater sales if the take-out rate were reduced and the prize pool increases.

\section{CONCLUSION}

This paper tested for addiction among lotto players. Earlier tests of addiction have tended to concentrate on physically addictive goods such as cigarettes. Our raw data suggests that there is quite considerable addiction and that this is essentially induced by rollovers, since sales are higher than average after a rollover. However, lotto play is found to be less addictive than physically addictive goods such as cigarette consumption.

The price elasticity is identified through changes in the expected value of holding a ticket, variations in which are driven exogenously by rollovers and, surprisingly, we find that the implied long-run elasticity is estimated with sufficient precision to reject revenue maximisation (which is what the regulator demands). Our results suggest that changing the distribution of sales revenue so that a higher proportion is allocated to prizes would generate a sufficiently large increase in sales that revenue to 'good causes' could be increased ${ }^{22}$.

University of Manchester

ESRI, Dublin,

University of Warwick.

Date of Receipt of Manuscript: September 1998.

\section{REFERENCES}

Andrews, D. (1993), Tests for Parameter Instability and Structural Change with Unknown Change Points, Econometrica Vol. 61, pp 821-56.

Becker, G. S. and Murphy, K. M. (1988), A Theory of Rational Addiction, Journal of Political Economy, Vol. 96, pp 675-700.

Becker, G. S., Grossman, M. and Murphy, K. M. (1994), An Empirical Analysis of Cigarette Addiction, American Economic Review, Vol. 84, pp 396-418.

Conlisk, J. (1993), Utility of Gambling, Journal of Risk and Uncertainty, Vol. 6, pp $255-75$.

Cook, P. J. and Clotfelter, C. T. (1993), The Peculiar Scale Economies of Lotto, American Economic Review, Vol. 83, pp 634-43.

Davidson, R. and MacKinnon, J. G. (1993), Estimation and Inference in Econometrics, Oxford University Press, New York.

\footnotetext{
${ }^{22}$ Of course, this pricing recommendation is conditional on the policy goal of revenue maximisation. It is unclear why this should be appropriate for lotto since it seems unlikely that the tax treatment of any other good is predicated on maximising revenue from taxing it. Moreover, deriving welfare implications in the context of endogenous preferences is a treacherous area.
} 
Dickey, D. A. and Fuller, W. A. (1981), Likelihood Ratio Statistics for Autoregressive Time Series with Unit Roots, Econometrica, Vol. 49, pp 1057-72.

Dickey, D. A. and Fuller, W. A. (1979), Distribution of the Estimators for Autoregressive Time Series with Unit Roots, Journal of the American Statistical Association, Vol. 74, pp 427-31.

Engle, R. F. (1982), Autoregressive Conditional Heteroskedasticity, with Estimates of the Variance of UK Inflation, Econometrica, Vol. 50, pp 987-1007.

Farrell, L., Hartley, R., Lanot, G. and Walker, I. (1999), 'The Demand for Lotto: the Role of Conscious Selection, Journal of Business and Economic Statistics, (forthcoming).

Farrell, L. and Walker, I. (1998), The Welfare Effects of Lotto: Evidence for the UK, Journal of Public Economics, Vol. 72, pp 99-120.

Granger, C. and Newbold, P. (1974), Spurious Regressions in Econometrics, Journal of Econometrics, Vol. 2, pp 111-20.

Gulley, O. D. and Scott, F. A. (1993), The Demand for Wagering on State Operated Lotto Games, National Tax Journal, March, pp 13-22.

Hansen, B. (1992), Testing for Parameter Stability in Linear Models, Journal of Policy Modelling, Vol. 14, pp 517-33.

Lim, F. W. (1995), On the Distribution of Lotto, Australian National University WP 282.

Nyblom, J. (1989), Testing for the Constancy of Parameters over Time, Journal of the American Statistical Association, Vol. 84, pp 223-30.

OFLOT, (1995), Annual Report 1994/95 HMSO 755.

Quiggin, J. (1991), On the Optimal Design of Lotteries, Economica, Vol. 58, pp 116.

Scoggins, J. (1995), Lotto and Expected Net Revenue, National Tax Journals Vol. 48, pp 61-70.

Sprowls, C. R. (1970), On the Terms of the New York State Lottery, National Tax Journal, Vol. 23, pp 74-82.

Zivot, E. and Andrews, D. (1992), Evidence of the Great Crash, the Oil Price Shock and Unit Roots, Journal of Business and Economic Statistics, Vol. 10, pp 25170 . 